\title{
A Distinct Subset of Tenascin/CS-6-PG-Rich Astrocytes Restricts Neuronal Growth in vitro
}

\author{
Sally Meiners, ${ }^{1}$ Elizabeth M. Powell, ${ }^{2}$ and Herbert M. Geller ${ }^{1}$ \\ 'Department of Pharmacology, UMDNJ-Robert Wood Johnson Medical School, and ${ }^{2}$ The Graduate School, Rutgers \\ University, Piscataway, New Jersey 08854
}

\begin{abstract}
Astrocytes provide an optimal surface for attachment, migration, and growth of CNS neurons. Nonetheless, not all astrocytes are alike: our previous work demonstrated a heterogeneity in the ability of cultured astrocyte monolayers to support neuronal growth. Areas displaying a fibrous, uneven surface ("rocky" astrocytes) were shown to be restrictive substrates, whereas surrounding, flat areas were permissive substrates. However, whether these cell types are in fact different cannot be addressed using mixed cultures. Therefore, in the current study we used morphological criteria to isolate the two subpopulations from mixed astrocyte cultures established from the cerebral cortex of neonatal rats. Following isolation, the purified populations only produced progeny with the same phenotype as the parent cells. We then measured production of several extracellular matrix molecules putatively involved in neuronal guidance during development and quantitatively assessed neuronal behavior on the purified populations. Immunocytochemistry and immunoblotting showed that rocky astrocytes were enriched in tenascin and chondroitin-6-sulfate- containing proteoglycans, but not in laminin or fibronectin. In addition, these astrocytes, as well as thelr Isolated matrix, were a less permissive substrate for neuronal growth than flat astrocytes/matrix. Neurite outgrowth was significantly increased on rocky astrocytes following treatment with chondroitinase $A B C$ or $A C$, but not heparitinase or hyaluronidase. These data support a critical role for matrix-bound chondroitin-6-sulfate-containing proteoglycans. We hypothesize that rocky astrocytes represent a subtype of cells which form barriers to neuronal growth during cortical development.
\end{abstract}

[Key words: tenascin, chondroitin sulfate proteoglycan, extracellular matrix, astrocyte/neuron interactions, development, regeneration]

Interactions between neurons and glia shape CNS development. The major classes of macroglia, oligodendrocytes and astrocytes, are biochemically and functionally distinct. Oligodendrocytes synthesize myelin and related proteins, and their function appears to be the ensheathment of neurons to increase the velocity of nerve conduction (Mirsky et al., 1980; Raff, 1989). Astro-

\footnotetext{
Received May 12, 1995; revised Aug. 3, 1995; Aug. 8, 1995.

This work was supported by NIH Grant NS 24168 to H.G. and by NIH NRS^ 09281 to S.M.

Correspondence should be addressed to Dr. Sally Meiners, Department of Pharmacology, UMDNJ-Robert Wood Johnson Medical School, 675 Hoes Lane, Piscataway, NJ 08854

Copyright (C) 1995 Society for Neuroscience $0270-6474 / 95 / 158096-13 \$ 05.00 / 0$
}

cytes are characterized by their expression of glial fibrillary acidic protein (GFAP) (Bignami et al., 1972), and their function is still a matter of active interest. Early in development, astrocytes shape neuronal migration and neurite outgrowth (Rakic, 1971; Silver et al., 1982), providing both positive and negative pathfinding cues (Pindzola et al., 1993). In the adult, mature astrocytes may provide trophic support for continued neuronal survival and may even inhibit additional growth (Fawcell el al., 1989; Smith et al., 1990).

The diverse functions of astrocytes are likely to reflect further heterogeneity in the astrocyte population. Even within the same brain region, astrocytes exhibit differences in neurotransmitter uptake (Johnstone et al., 1986) and expression of receptors (Trimmer and McCarthy, 1986), surface glycoproteins (Barbin et al., 1988; Vaysee and Goldman, 1992), and extracellular matrix (ECM) molecules (Crossin et al., 1986; Pindzola et al., 1993). Astrocytes are also morphologically heterogeneous: early in vivo studies defined fibrous and protoplasmic astrocytes, found mainly in white or grey matter, respectively (Ramon y Cajal, 1909; Peters et al., 1991). Astrocytes in culture also exhibit morphological, as well as antigenic, diversity, for example, type-1 and type-2 astrocytes (Raff et al., 1983). Other studies have demonstrated five morphologically distinct types of astrocytes in rat spinal cord cultures (Miller and Szigeti, 1991).

Our work has demonstrated heterogeneity in type- 1 astrocytes both in terms of morphology and ability to support neuronal growth. Embryonic neurons will avoid a subpopulation of astrocytes (termed "rocky") that is characterized by a fibrous, uneven morphology and increased tenascin expression; neurons grow well on surrounding flat astrocytes (Grierson et al., 1990). However, whether these cell types are in fact unique cannot be addressed using mixed cultures. To address this question in the current study, we isolated the astrocyte populations from mixed monolayers, measured their production of several molecules thought to be involved in neuronal guidance during development, and quantitatively assessed the behavior of neurons on the purified populations. Cells were separated by morphological criteria, dissociated, plated at low density, and grown to confluence. The confluent cultures retained the distinctive phenotypes of the parent cells. As in mixed monolayers, rocky astrocytes contained elevated levels of tenascin and similar levels of laminin and fibronectin; they were also found to contain elevated levels of chondroitin-6-sulfate-containing proteoglycans (CS-6PG) and were poor substrates for neuronal adhesion and process extension. These properties strongly resemble those of the boundary-forming astrocytes that provide negative cues for nellrite growth during development in vivo (Pindzola et al., 1993). 
Neurite outgrowth on rocky astrocytes was significantly enhanced following chondroitinase treatment; however, flat astrocytes were still a more permissive substrate. Similar to living cells, neurite outgrowth was less robust on rocky as opposed to flat matrix. Rocky astrocytes therefore exhibit a constellation of properties that negatively impact on neuronal development and regeneration and provide a model system for assessing the relative contributions of tenascin, CS-6-PG, and other ECM components in these processes.

\section{Materials and Methods}

Materials. Sprague-Dawley rats were purchased from Charles River Breeding Laboratories, Inc. (Wilmington, M $\Lambda$ ). Basal Media Eagle (BME), Dulbecco's Modified Eagle's Medium (DMEM), and fetal calf serum (FCS) were purchased from GIBCO Laboratories (Grand Island, NY). Antisera against human tenascin, rat fibronectin, and cow GFAP were obtained from GIBCO-BRL (Gaithersburg, MD), Chemicon (Temecula, CA), and DAKO Corp. (Carpinteria, CA), respectively. Monoclonal antibodies against 6-sulfated or 4-sulfated chondroitin or dermatan sulfate stubs of chondroitinase ABC-digested human proteoglycans were purchased from ICN Biomedicals (Costa Mesa, CA). Monoclonal antibodies against mouse GFAP and affinity isolated antibody against mouse laminin were purchased from Sigma Chemical Co. (St. Louis, MO). Nitroblue tetrazolium and 5-bromo-4-chloro-3-indoylphosphate were obtained from Kirkegard and Perry Laboratories Inc. (Gaithersburg, MD). Chondroitinase ABC, chondroitinase AC, heparitinase, and hyaluronidase (hyaluronoglucosidase) were obtained from ICN Biomedicals. All other chemicals and supplies were purchased from Sigma Chemical Co., Bio-Rad Laboratories (Richmond, CA) or Fisher Scientific (Sprimgfield, NJ).

Astrocyte cell culture. Rat cerebral cortical astrocytes were prepared according to a method adapted from McCarthy and de Vellis (1980). Cerebral cortices from postnatal day 1 Sprague-Dawley rats were removed and placed into BME with $0.02 \mathrm{M}$ HEPES buffer. The meningeal tissue and as much white matter as possible was removed. The remaining tissue was finely minced with dissecting knives and then trypsintreated $(0.025 \%)$ for $20 \mathrm{~min}$. The cells were pelleted by centrifugation at $1000 \mathrm{rpm}$ for $5 \mathrm{~min}$ and resuspended in $5 \mathrm{ml}$ of serum-containing medium composed of DMEM supplemented with $10 \%$ FCS and 2.2 $\mathrm{mg} / \mathrm{ml} \mathrm{NaHCO}$. One milliliter of $0.025 \%$ soybean trypsin inhibitor and $0.05 \%$ DNase was added to the mixture, and the tissue was triturated several times through a fire-polished Pasteur pipette. The cell solution was passed through a fine nylon mesh and placed into $80 \mathrm{~cm}^{2}$ poly-Llysine (PLL)-coated culture hasks at a final density of from 2 to $4 \times$ $10^{6}$ cells/flask. Once the astrocytes reached confluence (approximately $10 \mathrm{~d}$ to 2 weeks), the flasks were shaken overnight on a rotary shaker to remove loosely adherent, contaminating top cells (oligodendrocytes, neurons, and macrophages). Astrocytes are routinely screened via immunofluorescence techniques for the expression of GFAP as well as for oligodendrocyte and neuronal markers, and this culture method generally yields $>95 \%$ GFAP-positive cells.

As cultures with particularly pronounced, and distinct, flat and rocky areas were identified, these areas were carefully removed from the flask with a sterile spatula, trypsinized, and triturated to form a single cell suspension. Astrocytes then were replated onto PLL-coated $12 \mathrm{~mm}$ round glass coverslips in 24-well trays at low density $\left(1-2 \times 10^{2}\right.$ cells/ well) for immunocytochemistry assays or at medium density $(1-2 \times$ $10^{3}$ cells/well) for neurite outgrowth assays. Other astrocytes were replated at medium density $\left(2-3 \times 10^{3}\right.$ cells/well $)$ in PLL-coated 12 -well trays for Western blotting or onto PLL-coated $13 \mathrm{~mm}^{2}$ etched grid coverslips (Bellco Glass Inc., Vineland, NJ) in 12-well trays for neuronal adhesion assays.

Neuronal cell culture. Hypothalamic and mesencephalic neuronal cultures were prepared as described by Ventimiglia and Geller (1987). Hypothalamic neurons were chosen for this study because they were the type of neuron used in the original work describing rocky astrocytes (Grierson et al., 1990). Mesencephalic neurons were chosen because we wished to determine whether the growth restrictive effects extended to more than one type of neuron. Embryonic rats were isolated from timedpregnant females by caesarian section. The appearance of a sperm plug was defined as embryonic day 1 (E1); neuronal cultures were cultivated between E14 and E18. Embryonic brains were removed into a Petri dish containing $5 \mathrm{ml}$ of BME-HEPES. Meninges were peeled off, and selected brain regions (hypothalamus; mesencephalon) were removed and minced into fine pieces $(<0.5 \mathrm{~mm})$ with dissecting knives. Anty remaining meninges and blood vessels were removed at this time to ensure minimal contamination from endothelial cells. The minced tissue was then incubated in BME-HEPES containing $0.025 \%$ trypsin and $0.1 \%$ collagenase for $30 \mathrm{~min}$ at $37^{\circ} \mathrm{C}$. Following incubation, the trypsinization was halted by adding $1 \mathrm{ml}$ of DMEM $/ 10 \%$ FCS containing $0.025 \%$ soy bean trypsin inhibitor and $0.05 \%$ DNAse I. The tissue was then gently triturated through a fire-polished Pasteur pipette until it was dispersed into a homogeneous suspension. The suspension was filtered through a fine nylon mesh ( $40 \mu \mathrm{m}$, Tetko) and centrifuged for $5 \mathrm{~min}$ at $1000 \mathrm{rpm}$. The pellet of embryonic cells was resuspended in fresh serum-containing medium and used for ncuronal adhesion and neuritc outgrowth assays as described below.

Identification of extracellular matrix molecules and GFAP in astrocyte extracts. Astrocytic tenascin, chondroitin-6-sulfate-containing proteoglycans (CS-6-PG), chondroitin-4-sulfate- containing proteoglycans (CS-4-PG), fibronectin, laminin, and GFAP were identified using immunoblotting techniques. The CS-6-PG antibody recognizes chondroitin-6-sulfate stubs of high density proteoglycans following a $1 \mathrm{hr}$ incubation of cells with $0.1 \mathrm{U} / \mathrm{ml}$ chondroitinase $\mathrm{ABC}$ at $37^{\circ} \mathrm{C}$; the $\mathrm{CS}$ 4-PG antibody recognizes chondroitin-4-sulfate or dermatan sulfate (DS) stubs. Astrocyte cultures were removed from 12-well chambers by aspirating off the media, rinsing the cells with $0.5 \mathrm{M}$ ethylenediaminetetraacetate (EDTA), and scraping the cells into $150 \mu \mathrm{l}$ of Laemmli sample buffer (Laemmli, 1970) using a rubber policeman. Protein concentrations were determined using the Bio-Rad-DC protein assay. Cell extracts $(20 \mu \mathrm{g})$ were subjected to sodium dodecyl sulfate polyacrylamide gel electrophoresis (SDS-PAGE) (Laemmli, 1970) and then transferred to nitrocellulose paper (400 mA, $1.5 \mathrm{hr}$ ) (Towbin et al,, 1979). The blots were incubated in blocking solution containing $5 \%$ dry milk (Carnation brand) in Tris-buffered saline (TBS: $20 \mathrm{~mm}$ Tris- $\mathrm{HCl} \mathrm{pH}$ $7.5,0.5 \mathrm{M} \mathrm{NaCl}$ ) for $2-4 \mathrm{hr}$. They were then incubated overnight in a solution of the appropriate primary antibody (rabbit anti-tenascin, mouse anti-CS-4-PG, mouse anti-CS-6-PG, rabbit anti-fibronectin, rabbit anti-laminin, or rabbit anti-GFAP) diluted 1:1000 (1:200 for antiCS-4-PG and anti-CS-6-PG) in 3\% dry milk/TBS and washed. The washing procedure consisted of four $10 \mathrm{~min}$ washes in TBS containing $0.05 \%$ Tween 20 . The blot was then incubated with alkaline phosphatase- conjugated goat anti-rabbit or goat anti-mouse IgG (Sigma Chemical $(0$.$) at a 1:000 dilution and washed as above. Bound tenascin,$ fibronectin, or laminin antibody was detected colorimetrically using 5-bromo-4-chloro-3-indoyl-phosphate and nitroblue tetrazolium. All antibody incubations and washes were done at room temperature.

Quantification of tenascin and GFAP production. The relative intensities of the tenascin and GFAP bands in purified cultures were compared and quantified as we have described previously (Meiners et al., 1993). Immunoblots were scanned at 600 dots per inch and 256 gray scalc resolution on a Microtek $600 \mathrm{G}$ scanner. Images were analyzed using the NIH IMAGE program (available by anonymous FTP from zippy.nimh.nih.gov) with the Gel Analysis Macro routine. A profile of intensities of immunoreactivity within each lane was first created and used as an indication of the level of tenascin or GFAP production. Immunoblots containing serial dilutions of cell extracts were also scanned, and the intensity values were found to increase with increasing volumes of cell extract. Within each gel, the levels of tenascin or GFAP expression in rocky astrocytes were normalized to the level in flat cultures, which was assigned a value of 1 . Only astrocytes from the same parent culture were compared to each other in these experiments. The data from several independent experiments was then pooled and analyzed using the INSTAT program (GraphPad Software, La Jolla, CA).

Immunofluorescence analysis. Astrocyte cultures were double-labeled with rabbit polyclonal antiserum against tenascin and monoclonal antibody against GFAP or with monoclonal antibody against CS-6-PG and polyclonal antiserum against GFAP. For CS-6-PG labeling, astrocytes were first digested with chondroitinase $\mathrm{ABC}$ as described above for $\mathrm{CS}$ 6-PG immunoblots. Fluorescently conjugated secondary antibodies were obtained from Organon-Technika Cappel. Cell cultures on glass coverslips in 24-well chambers were incubated with anti-tenascin or anti-CS-6-PG diluted 1:100 in phosphate-buffered saline (PBS: $0.14 \mathrm{M}$ $\mathrm{NaCl}, 2.7 \mathrm{~mm} \mathrm{KCl}, 1.5 \mathrm{mM} \mathrm{KH} \mathrm{PO}_{4}, 4.3 \mathrm{~mm} \mathrm{NaHPO}_{4}$ ) containing $0.1 \%$ sodium azide (PBS-azide) and 10\% FCS (PBS azide-serum) for $30 \mathrm{~min}$ at $4^{\circ} \mathrm{C}$. After rinsing in PBS-azide, the coverslips were incubated with fluorescein-conjugatcd sccondary antibodics (goat anti-rabbit for tenascin and goat anti-mouse for CS-6-PG) diluted 1:100 in PBS azide- 
serum for $30 \mathrm{~min}$ at $4^{\circ} \mathrm{C}$. The astrocytes were again rinsed in PBS-azide and fixed by submerging the coverslips in acetic acid/ethanol (5\%/95\%) for $5 \mathrm{~min}$ at $-20^{\circ} \mathrm{C}$. After rinsing in PBS-azide-serum, the incubation and rinse steps were then repeated using monoclonal mouse anti-GFAP and rhodamine-conjugated goat anti-mouse secondary antibody (Organon-Technika Cappel) for the anti-tenascin-labeled coverslips and polyclonal anti-GFAP and rhodamine-conjugated goat anti-rabbit secondary antibody for the anti-CS-6-PG-labeled coverslips. After the final incubation, coverslips were rinsed in PBS-azide and mounted in Citifluor (City of I ondon Polytechnic) on microscope slides. Nonspecific binding of secondary antibodies was controlled for by omitting the appropriate primary antibody in parallel cultures. Cultures were examined using a Zeiss $\Lambda$ xioplan microscope equipped with an epifluorescence illuminator with fluorescein and rhodamine filters. Photographs were taken using Kodak TMAX 400 film.

Neuronal adhesion assays. Neuronal adhesion assays were conducted as described in our previous work (Petroski et al., 1991). Embryonic day 17 (E17) hypothalamic or E15 mesencephalic cells were plated at 20,000 cells/well onto astrocyte monolayers grown on etched grid coverslips in 12-well chambers. The cells were allowed to settle and adhere for $1 \mathrm{hr}$. Cultures were then shaken at $75 \mathrm{rpm}$ on a horizontal rotating platform in a $37^{\circ} \mathrm{C}$ incubator for $60 \mathrm{~min}$, rinsed four times with fresh medium, and then fed. At $48 \mathrm{hr}$ cultures were incubated with the dye carboxyfluorescein diacetate (CFDA) $(10 \mu \mathrm{g} / \mathrm{ml})$ for $30 \mathrm{~min}$ at $37^{\circ} \mathrm{C}$ and rinsed for an additional $30 \mathrm{~min}$ with medium. Under these conditions only viable neurons retain the dye and exhibit fluorescence (Grumet et al., 1983; Petroski and Geller, 1994). Coverslips of living cells were examined under fluorescein optics, and CFDA-labeled neurons were counted in nonoverlapping fields (equivalent to approximately 15 $\mathrm{mm}^{2}$ ) of the coverslip.

Neurite outgrowth assays. Dissociated E15 mesencephalic cells were plated onto astrocyte monolayers at 10,000 cells/well in 24-well chambers. Coverslips were labeled with CHDA 24,48 , and $72 \mathrm{hr}$ after plating. CFDA intensely stains the soma and all processes of cultured, living neurons. Images of the cultures were captured using a Macintosh Quadra 700 with a Scion LG-3 frame grabber board and analyzed with the NIH IMAGE software. The length of each primary process and its hranches was measured for at least 50 neurons for each condition. The total neuritic length for each neuron was calculated as the sum of the lengths of individual neurites.

Enzymatic treatment of astrocyte monolayers. Astrocytes in 24-well chambers were treated with either chondroitinase $\mathrm{ABC}$, chondroitinase $\mathrm{AC}$, heparitinase, or hyaluronidase/hyaluronoglucosidase. [Chondroitinase ABC degrades chondroitin-6-sulfate (CS-6), chondroitin-4-sulfate (CS-4), and dermatan sulfate (DS) to 4,5-unsaturated disaccharides by elimination. Chondroitinase AC degrades CS-6 and CS-4 but not DS. Heparitinase catalyzes the eliminative cleavage of heparan sulfate but also has slight chondroitinase activity. Hyaluronidase specifically cleaves hyaluronic acid. For a more detailed description of the specifications of these enzymes, see the ICN product analysis sheets.] After aspirating off the culture media, the astrocytes were covered with one of the following enzyme solutions for $4 \mathrm{hr}$ at $37^{\circ} \mathrm{C}:$ (1) chondroitinase $\mathrm{ABC}, 0.1 \mathrm{unit} / \mathrm{ml}$, in $0.1 \mathrm{M}$ Tris acetate buffer, $\mathrm{pH} 8.0$; (2) chondroitinase $\mathrm{AC}, 0.1 \mathrm{unit} / \mathrm{ml}$ in $0.1 \mathrm{M}$ Tris acetate buffer, $\mathrm{pH} 7.3$; (3) heparitinase, $1 \mathrm{unit} / \mathrm{ml}$ in $0.1 \mathrm{M}$ PBS, $\mathrm{pH} 7.3$; or (4) hyaluronidase, 5 units $/ \mathrm{ml}$ in $0.1 \mathrm{M} \mathrm{Na}$ acetate buffer, pH 5.0. The enzyme solution was removed and replaced with fresh media. E15 mesencephalic cells were plated onto the enzyme-treated astrocytes at a density of 10,000 cells/well and processed for neurite outgrowth assays 24 and $48 \mathrm{hr}$ after plating.

Growth of neurons on extracellular matrix. Matrices were prepared from cultures grown in 24-well chambers according to the methods of Smith-Thomas et al. (1994). Briefly, confluent cells were washed twice with Hanks' balanced salts solution and treated with distilled water containing $0.2 \%$ Triton X-100 twice for 20 min; the cellular debris was then vigorously washed away with a Pasteur pipette. The matrix preparations were washed twice with distilled water. E15 mesencephalic cells were plated onto the matrix in serum-containing medium at a density of 10,000 cells/well. Cultures were processed for neurite outgrowth assays 24 and $48 \mathrm{hr}$ after plating.

\section{Results}

Isolation of astrocyte subpopulations from mixed monolayers

Cerebral cortical astrocytes were cultivated from nennatal rats, and flat and rocky areas of heterogenous monolayers were iden- tified. Figure $1 A$ depicts a typical rocky clump of cells, similar to those described by Grierson et al. (1990), surrounded by flat cells. The rocky areas are generally fairly small as shown, although they do vary in size from only a few cells to several millimeters in diameter. As particulary pronounced rocky and flat regions arose, these were subcultured onto PLL-coated coverslips in $10 \%$ serum-containing medium at $1-2 \times 10^{2}$ cells/well as described in Materials and Methods.

Astrocytes subcultured at $1-2 \times 10^{2}$ cells/well were plated down as distinct single cells so as to disrupt any homotypic epigenetic signaling potentially required to maintain one form or the other that may have been provided by cells remaining in sheets or clumps. $\Lambda$ fter reaching confluence, the flat cells continued to demonstrate a flat morphology (Fig. 1B) whereas the rocky cells demonstrated a fibrous, uneven morphology (Fig. $1 C$ ). The fact that the astrocyte populations maintain their phenotypic differences after replating suggests that they may represent different subtypes of glial cells, as opposed to, for example, different stages of astrocyte maturity.

While subculturing astrocytes at this low density allowed us to follow the fate of individual cells, the cells grew very slowly and required up to two months to reach confluence. Therefore, we grew astrocytes at a density of $1-2 \times 10^{2}$ cells/well for immunofluorescence experiments and at a density of $1-2 \times 10^{3}$ cells/well for experiments requiring larger amounts of biological material (e.g., SDS-PAGE and immunoblot analysis, neuronal adhesion and neurite outgrowth assays). However, rocky astrocytes did grow more rapidly than flat astrocytes (data not shown). This distinguishes them from type- 2 astrocytes, which have a low proliferative activity (Raff et al., 1983), as does the fact that they lack A2B5, the type-2 astrocyte marker (Eisenbarth et al., 1979) (data not shown).

\section{Production of tenascin, CS-6-PG, CS-4-PG, fibronectin, laminin, and $G F A P$}

Cell extracts from flat and rocky astrocytes were separated on SDS-PAGE gels, transferred to nitrocellulose paper, and probed with tenascin antiserum. The immunoblot with tenascin antiserum revealed three polypeptide bands for both extracts with $M_{\text {r }}$ $190,000,200,000$, and 240,000 (Fig. 2), which is in agreement with the subunit molecular weights previously reported for rat tenascin (Chiquet-Ehrismann et al., 1986; Meiners et al., 1993). Immunoblot analysis showed that all three tenascin isoforms were increased for rocky astrocytes. Immunoblots were analyzed by quantitative scanning densitometry. Tenascin production was increased an average of 4.8 -fold and varied between $3.4-$ and 7.6-fold in five independent experiments (Fig. 3A). This experimental variation was probably due in part to the technical difficulty involved in obtaining pure populations of astrocytes by morphological criteria, or, alternatively, suggests that there may be several subclasses of "rocky" astrocytes with varying amounts of tenascin.

CS-6-PG and CS-4-PG production were also examined on immunoblots. Following digestion with chondroitinase $\mathrm{ABC}$, astrocytes were extracted, electrophoresed on SDS-PAGE gels, transferred to nitrocellulose paper, and probed with a monoclonal antibody against CS-6-PG or CS-4-PG (Fig. 2). Rocky extracts demonstrated three polypeptide bands that cross-reacted with the CS-6-PG antibody with $M_{r}$ 148,000, 246,000, and 388,000 whereas no bands were detected in flat extracts. In addition, no bands were detected in extracts of undigested cells (data not shown). The relative intensities of the three bands varied from 

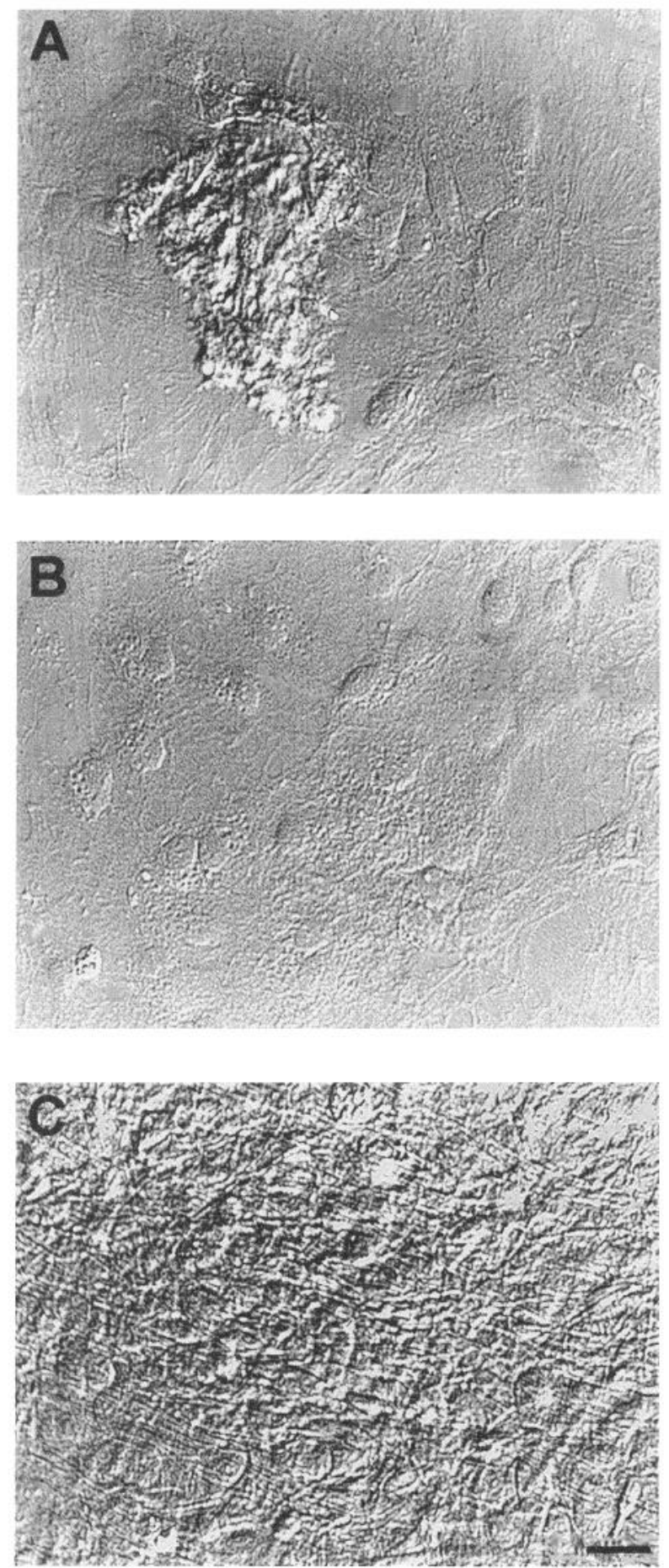

Figure 1. Isolation of flat and rocky populations of cultured rat cerebral cortical astrocytes from a heterogenous monolayer. $A$, Nomarski differential contrast optics depicting a confluent culture with a distinct rocky region (middle left) surrounded by a flat region. These regions were dissected out of the monolayer with a sterile spatula, trypsinized and triturated into a single-cell suspension, and replated on $12 \mathrm{~mm}$ glass coverslips. The flat cells remained flat after reaching confluence $(B)$, and the rocky cells remained rocky $(C)$. This suggests that the subpopulations represent two distinct phenotypes under the conditions of our cell culture system. Scale bar, $10 \mu \mathrm{m}$.
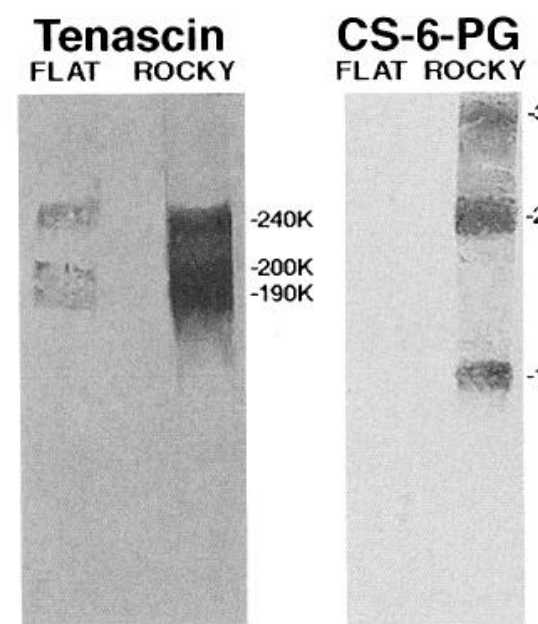

CS-4-PG

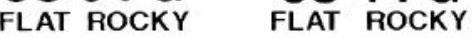

\section{Fibronectin FLAT ROCKY}

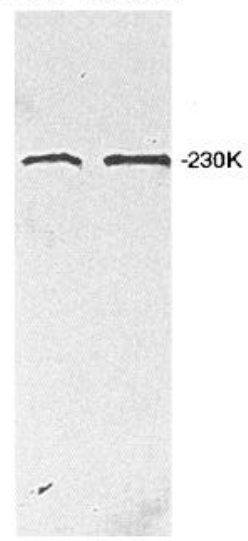

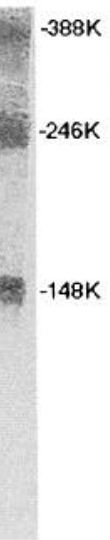
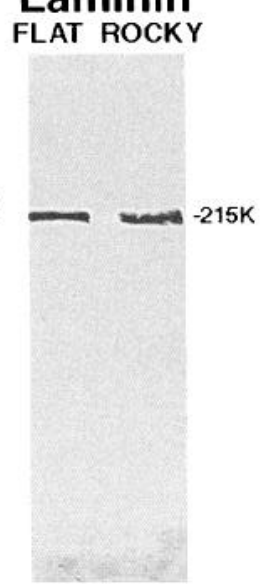

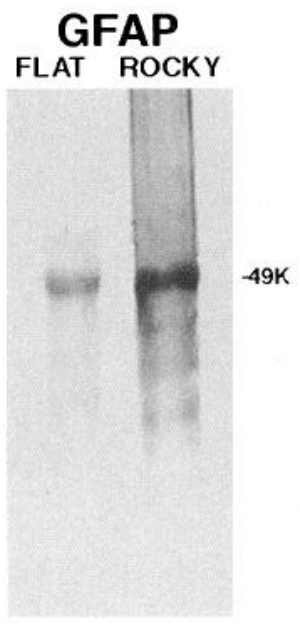

Figure 2. Immunoblot analysis of tenascin, CS-6-PG, CS-4-PG, fibronectin, laminin, and GFAP production. Cell extracts were resolved on SDS-PAGE gels (6\% acrylamide for ECM molecules, $12 \%$ acrylamide for GFAP), transferred to nitrocellulose paper, and probed with the appropriate primary antibody. Cells were digested with chondroitinase $\mathrm{ABC}$ prior to extraction for CS-6-PG and CS-4-PG immunoblots. Antibody binding was visualized using alkaline phosphatase-conjugated secondary antibodies (Sigma Chemical $\mathrm{Co}$.) according to the manufacturer's instructions. Rocky astrocytes demonstrated increased amounts of tenascin, CS-6-PG, and GFAP in comparison to flat astrocytes and similar amounts of fibronectin, laminin, and CS-4-PG.

experiment to experiment. The $M_{r} 148,000$ and 246,000 bands probably correspond to the 1D1 CS-6-PG proteoglycans (with $M_{r} 150,000$ and 245,000 ) reported in $7 \mathrm{~d}$ old rat brain by Rauch et al. (1991). Cloning studies (Rauch et al., 1992) have revealed that the smaller 1D1 proteoglycan is apparently derived from the larger, termed neurocan, via proteolytic processing. The $M_{r}$ 388,000 band probably corresponds to the $3 \mathrm{~F} 8$ proteoglycan (with $M_{r} 400,000$ ), also reported in $7 \mathrm{~d}$ old rat brain by Rauch et al. (1991). On the other hand, the CS-4-PG antibody failed to detect any cross-reactive bands in either flat or rocky extracts. As a positive control, the antibody did react with a polypeptide of $M_{r} 200,000$ in extracts of Neu7 cells (data not shown). Neu7, an immortalized astrocytic cell line, has been reported to express a dermatan sulfate-containing proteoglycan (DSPG) (Smith-Thomas et al., 1994).

We also investigated the production of fibronectin and laminin via immunoblotting techniques (Fig. 2). Fibronectin antiserum reacted with a polypeptide of $M_{r} 230,000$ for both astrocyte sub- 

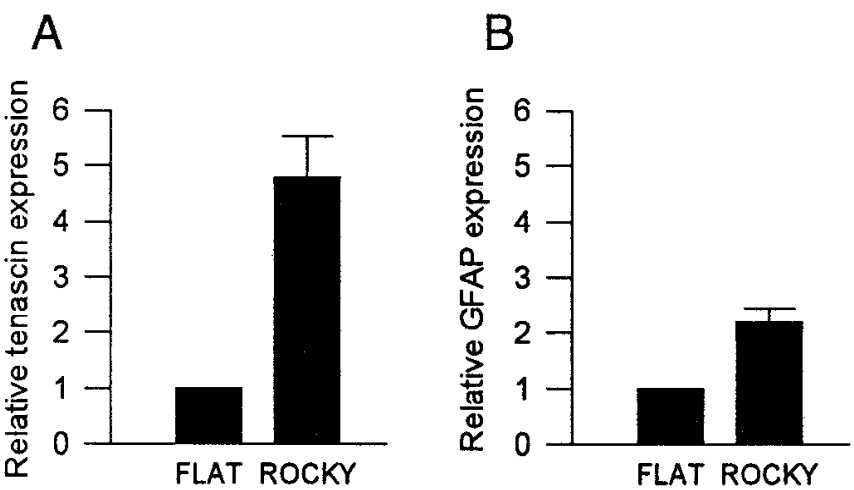

Figure 3. Quantification of tenascin and GFAP production. Tenascin and GFAP were visualized on immunoblots as in Figure 2. Immunoblots were scanned and the level of tenascin or GFAP in each lane was quantified and normalized to the level in flat cultures, which was assigned a value of 1 . Bars represent mean $(n=5) \pm$ the SE and were statistically significant (Student's $t$ test, $p<0.05$ ).

types. Laminin antibody reacted with a polypeptide band of $M_{r}$ 215,000 , which corresponds to the B1 chain of laminin. Laminin antibody occasionally reacted with a second polypeptide of $M_{r}$ 205,000 , which corresponds to the B2 chain of laminin (data not shown). Levels of fibronectin and laminin did not appear to vary greatly between flat and rocky astrocytes, confirming our previous immunocytochemical observations (Grierson et al., 1990) on mixed cultures. Our previous work showed that flat and rocky astrocytes in mixed monolayers also exhibited similar levels of the neurite outgrowth-promoting molecules thrombospondin and NCAM (Bixby et al., 1988; O'Shea et al., 1990; Neugebauer et al., 1991); early experiments demonstrate that this is true for isolated subpopulations as well (data not shown). Thus, the composition of the rocky matrix seems to be altered such that it is specifically enriched in negative regulators of neuronal growth while levels of positive regulators remain unchanged. Of course, the rocky matrix may also be deficient in levels of as yet unidentified positive regulators that are present in the flat matrix.

Finally, GFAP production was examined on immunoblots to confirm the identity of flat and rocky cells as astrocytes. GFAP antiserum reacted with a polypeptide of $M_{r} 49,000$ for both cell extracts. Scanning densitometry demonstrated that GFAP expression was increased an average of 2.2 -fold for rocky astrocytes and varied between 1.4- and 2.8-fold in five independent experiments (Fig. $3 B$ ).

\section{Immunocytochemistry of tenascin and CS-6-PG}

To evaluate whether the increasing tenascin and CS-6-PG production was reflected as an increase in cell-surface protein, astrocytes were double-labeled with antibodies against tenascin and GFAP (Fig. 4) or CS-6-PG and GFAP (Fig. 5). The tenascin staining was performed on living, unfixed cultures, while the GFAP staining was done after fixation and permeabilization. CS6-PG staining was performed on living, unfixed cultures following digestion with chondroitinase $\mathrm{ABC}$. The flat astrocytes showed a fairly low level of both tenascin (Fig. $4 E$ ) and CS-6PG (Fig. 5E) immunoreactivity. Rocky astrocytes demonstrated a much higher level of immunoreactivity for both proteins (Figs. $4 F, 5 F$ ). In contrast, when flat and rocky astrocytes were labeled with antibodies against CS-4-PG, little if any immunoreactivity was detected for either type of astrocyte (data not shown). The differences in tenascin and CS-6-PG levels were also found in mixed monolayers (data not shown). Note that the nuclei of rocky astrocytes were smaller (Figs. $4 B, 5 B$ ) than the nuclei of flat astrocytes (Figs. $4 A, 5 A$ ), an observation also made by Grierson et al. (1990) for mixed monolayers. Immunoreactivity for tenascin and CS-6-PG was punctate in appearance and restricted to areas of the cellular periphery, as is typical for extraccllular matrix proteins. These results therefore paralleled those obtained via immunoblot analysis and also confirmed that the tenascin antiserum and CS-6-PG antibodies recognized appropriately localized antigens. Morphological differences between flat and rocky cultures were made more obvious by GFAP staining (Figs. $4 C, D, 5 C, D)$. The rocky cultures depicted here were grown until nearly but not quite confluent (compare to fully confluent cultures in Fig. $1 C$ ) so as to more readily distinguish individual cells. The amount of tenascin and CS-6-PG did not appear to be correlated with the confluence of the cultures in that more or less confluent cultures did not express higher or lower amounts of these proteins (data not shown).

\section{Neuronal adhesion assays}

A recent study in our laboratory (Petroski et al., 1991) demonstrated that the differentiation of astrocytes by bFGF reduced their ability to support the adhesion and survival of hypothalamic neurons by about 7.7-fold. This reduction in neuronal adhesion may have been due in part to high levels of astrocytic tenascin and CS-6-PG which are induced by bFGF (Meiners et al., 1993). To evaluate whether neuronal adhesion was also reduced on tenascin/CS-6-PG-rich rocky astrocytes, dissociated E17 hypothalamic or E15 mesencephalic neurons were plated onto confluent monolayers of flat and rocky astrocytes grown on gridded coverslips. An adhesion assay was performed as described in Materials and Methods to evaluate specific neuronal attachment to the astrocyte substrate. Neuronal numbers were assessed at $48 \mathrm{hr}$ by counting CFDA-labeled cells bound to nonoverlapping fields of the coverslip in each of four separate experiments. Only process-bearing cells were counted on the flat astrocyte substrate. Because a large percentage of the neurons did not generate neurites on the rocky substrate (see below), all of the CFDA-labeled cells with an appropriate soma size were counted. Rocky astrocytes demonstrated a reduced ability to support neuronal adhesion in comparison to flat astrocytes (Fig. 6). There was an equivalent significant reduction in adhesion of both hypothalamic and mesencephalic neurons on rocky versus flat astrocytes ( $p<0.05$, two-way analysis of variance). The fact that neurons from two different brain regions behaved similarly on the astrocyte substrates suggests that the differential adhesion to the flat and rocky substrates is due to intrinsic properties of the astrocytes rather than to intrinsic properties of the neurons.

\section{Neurite extension on astrocyte monolayers}

Dissociated E15 mesencephalic cells were plated onto confluent monolayers of flat and rocky astrocytes and labeled with CFDA after 24,48 , or $72 \mathrm{hr}$. Extensive neurite outgrowth occurred on flat monolayers at $24 \mathrm{hr}$ (Fig. $7 A$ ), while neurons aggregated and extended few, if any, processes on rocky monolayers (Fig. $7 B$ ). After $48 \mathrm{hr}$ neurons extended some processes on the rocky substrate (Fig. $7 D$ ); however, these were shorter than those extended on flat monolayers (Fig. 7 C). A sizeable number of the neurons were still without neurites at this point. Neurites continued to extend on the flat substrate at $72 \mathrm{hr}$ (Fig. $7 D$ ), whereas they were not much longer on the rocky substrate than at $48 \mathrm{hr}$ (Fig. 

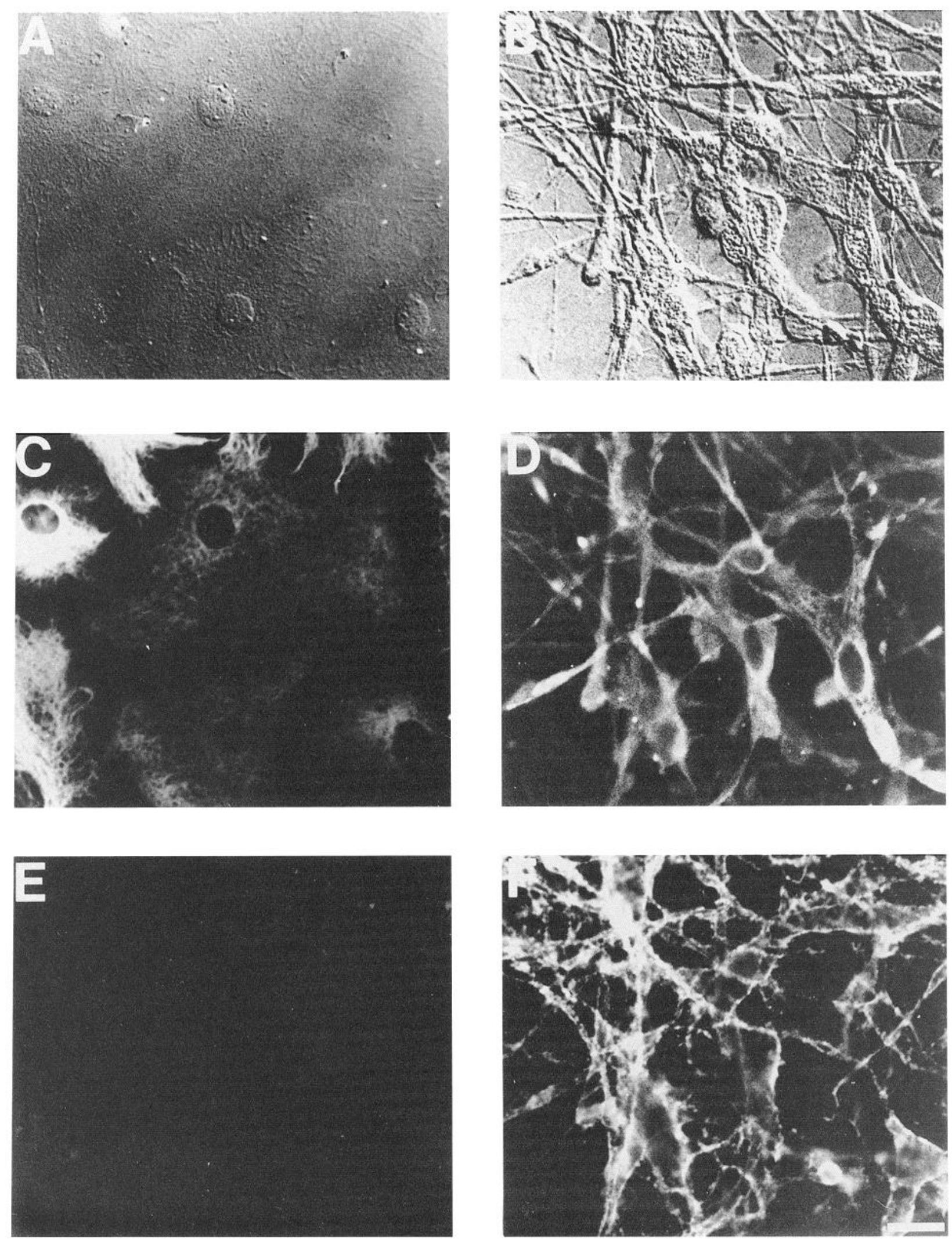

Figure 4. Immunocytochemistry of tenascin and GFAP. Living flat $(A, C, E)$ and rocky $(B, D, F)$ cultures were immunostained with polyclonal antibodies against tenascin followed by a fluorescein-conjugated secondary antibody, fixed, and reacted with monoclonal antibodies against GFAP followed by a rhodamine-conjugated secondary antibody. Photomicrographs illustrate Nomarski differential contrast optics $(A, B)$, GFAP immunoreactivity $(C, D)$, and tenascin immunoreactivity $(E, F)$. Rocky astrocytes demonstrated significantly higher levels of tenascin and somewhat higher levels of GFAP than flat astrocytes. Scale bar, $10 \mu \mathrm{m}$. 

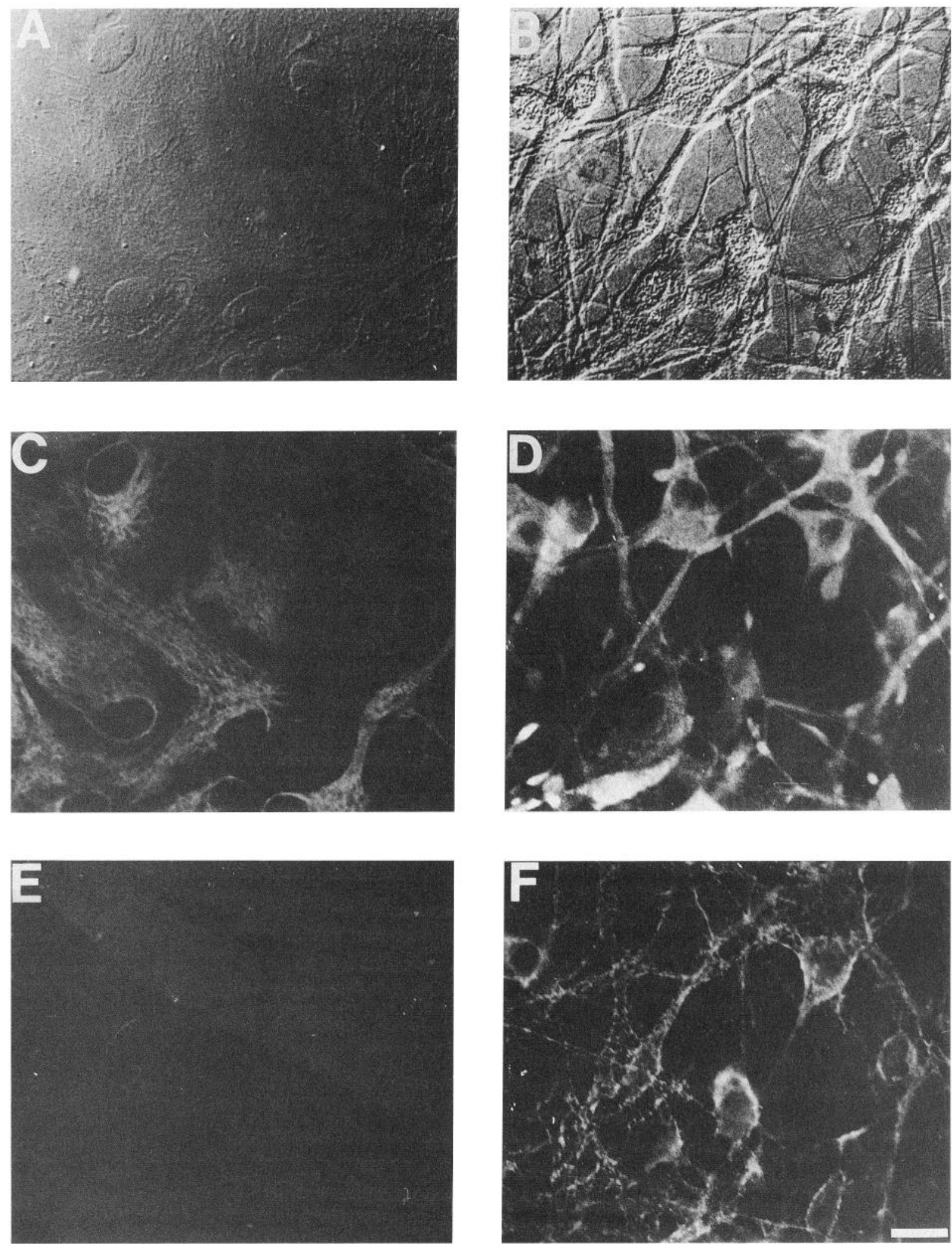

Figure 5. Immunocytochemistry of CS-6-PG and GFAP in flat $(A, C, E)$ and rocky $(B, D, F)$ astrocytes. Living cultures were treated with chondroitinase ABC, stained with monoclonal antibodies against CS-6-PG followed by a fluorescein-conjugated secondary antibody, fixed, and reacted with polyclonal antibodies against GFAP followed by a rhodamine-conjugated secondary antibody. Photomicrographs illustrate Nomarski differential contrast optics $(A, B)$, GFAP immunoreactivity $(C, D)$, and CS-6-PG immunoreactivity $(E, F)$. Rocky astrocytes demonstrated increased immunoreactivity for CS-6-PG and GFAP. Scale bar, $10 \mu \mathrm{m}$. 


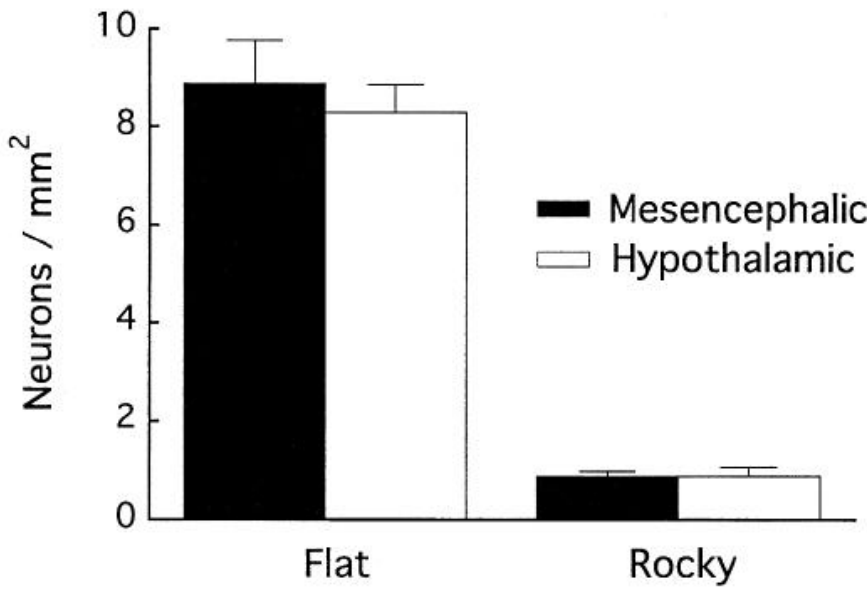

Figure 6. Neuronal adhesion on astrocyte monolayers. Dissociated E17 hypothalamic or E15 mesencephalic cells were plated on confluent monolayers grown on gridded coverslips. At $48 \mathrm{hr}$ neurons were labeled with carboxyfluorescein diacetate and counted in nonoverlapping fields of the coverslip. Bars represent mean \pm the SEM $(n=4)$ and were statistically significant ( $p<0.001$; two-way ANOVA). Rocky astrocytes demonstrated a reduced ability to support neuronal adhesion in comparison to flat astrocytes.

$7 F$ ). Neurites began to demonstrate some irregular blebs on the rocky substrate at $48 \mathrm{hr}$ and, increasingly, at $72 \mathrm{hr}$.

Because a very small number of the neurons had processes on the rocky substrate after $24 \mathrm{hr}$, we analyzed the ability of each astrocyte population to support neurite generation at 24 , 48, and $72 \mathrm{hr}$ (Fig. 8). At least 200 neurons were counted for each condition in three independent experiments. Neurites were defined as processes longer than one cell soma diameter. After $24 \mathrm{hr}$ only $7 \%$ of cells extended neurites on the rocky astrocytes, versus $78.3 \%$ of the cells on flat astrocytes. These numbers increased to $58.3 \%$ and $68.2 \%$ on rocky astrocytes versus $87.4 \%$ and $93.4 \%$ on flat astrocytes 48 and $72 \mathrm{hr}$, respectively. Neurite generation was therefore impaired on rocky astrocytes in comparison to flat astrocytes. This could be attributed to either the production of more or different inhibitory molecules (including but not limited to tenascin and CS-6-PG) by rocky astrocytes, or, alternatively, to the production of more or different growthpromoting molecules by flat astrocytes.

Neurite outgrowth studies were conducted for neurons that did extend processes longer than one cell soma diameter. Neurons were cocultured with monolayers of flat or rocky astrocytes for 24,48 , or $72 \mathrm{hr}$, at which time the extent of neurite outgrowth was determined. Neurite outgrowth studies were not conducted on rocky astrocytes at $24 \mathrm{hr}$ due to the paucity of neurons with neurites. We examined two parameters: the length of the longest neurite, and the combined length of all the neurites. Outgrowth values were plotted as cumulative histograms of the length of the longest neurite (Fig. 9A) or the total neuritic length (Fig. $9 B)$. A curve shifted to the right indicates that the neurites were longer for the entire population. Most of the outgrowth on the flat astrocytes occurred during the first $48 \mathrm{hr}$ with less outgrowth between 48-72 hr (Fig. 9). The median length of the longest neurite for neurons grown on flat astroctytes was $60 \mu \mathrm{m}$ at 24 hr; this value increased to $130 \mu \mathrm{m}$ at $48 \mathrm{hr}$ and $147 \mu \mathrm{m}$ at 72 hr. By comparison, no outgrowth was seen on the rocky astrocytes after $24 \mathrm{hr}$, and the median length of the longest neurite was $61 \mu \mathrm{m}$ at $48 \mathrm{hr}$ and $83 \mu \mathrm{m}$ at $72 \mathrm{hr}$. Two points can therefore be made from these graphs: first, both the length of the
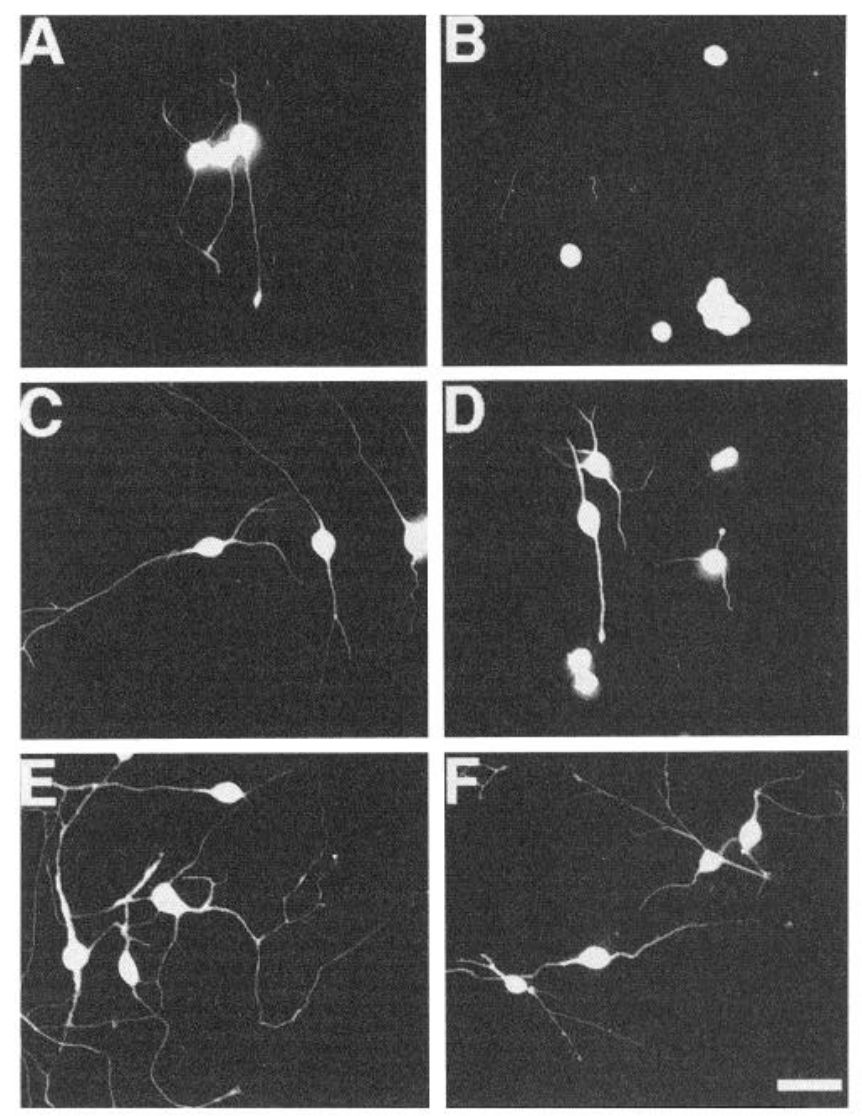

Figure 7. Appearance of neurons on astrocyte subpopulations. E15 mesencephalic neurons were plated onto flat $(A, C, E)$ and rocky astrocytes $(B, D, F)$, allowed to extend processes for $24(A, B), 48(C, D)$, or $72 \mathrm{hr}(E, F)$, and labeled with CFDA. Neurites were visibly shorter on the rocky substrate at each time point. Scale bar, $10 \mu \mathrm{m}$.

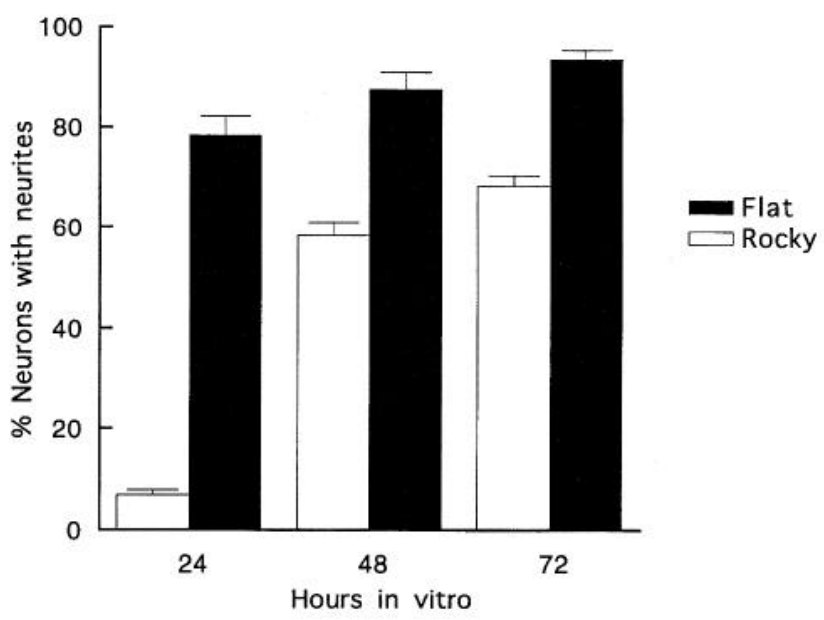

Figure 8. Neurite generation on astrocyte subpopulations. Dissociated E15 mesencephalic cells were plated on confluent astrocyte monolayers and allowed to extend processes for 24,48 , or $72 \mathrm{hr}$. The percentage of cells with neurites longer than one cell soma diameter (out of 200 cells total) was assessed for each time point. Bars represent mean \pm $\operatorname{SEM}(n=3)$ and were statistically significant $(p<0.001$; two-way ANOVA). Neurite generation was inhibited on the rocky substrate in comparison to the flat substrate, particularly at the $24 \mathrm{hr}$ time point. 


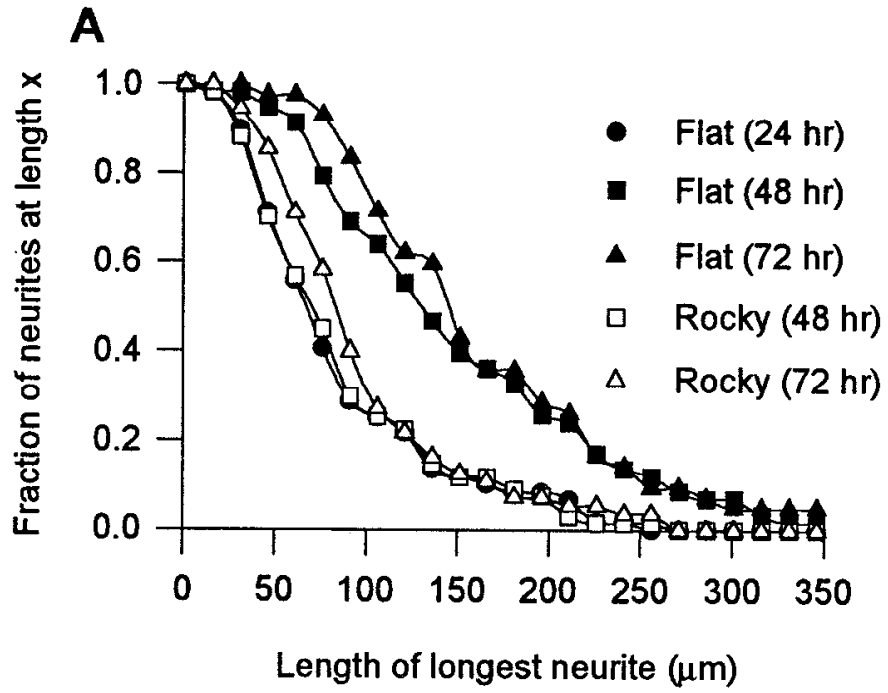

B

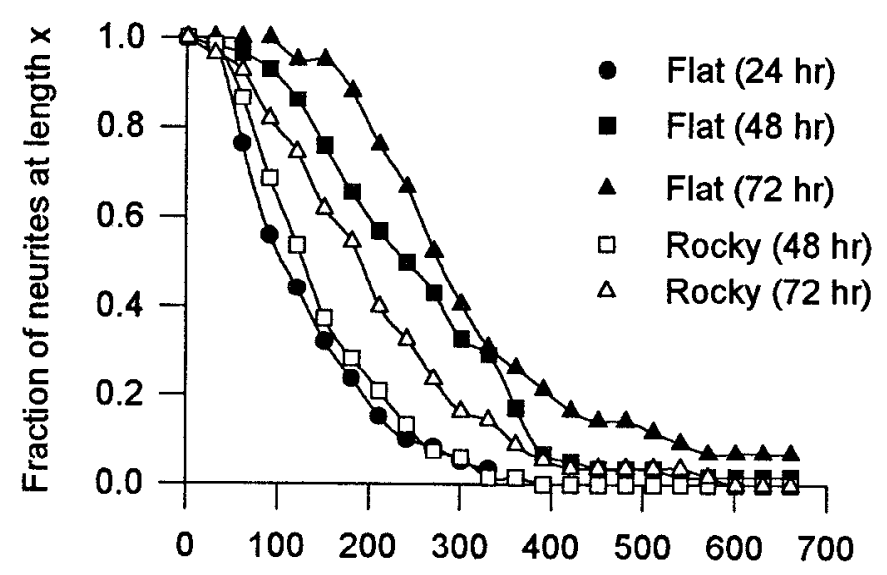

Total neuritic length $(\mu \mathrm{m})$

Figure 9. Neurite outgrowth on astrocyte subpopulations. E15 mesencephalic cells were allowed to extend processes on flat and rocky astrocyte monolayers for $24 \mathrm{hr}, 48 \mathrm{hr}$, or $72 \mathrm{hr}$. At least 50 neurons with processes greater than one soma diameter were considered for each condition. Distributions of both the length of the longest neurite $(A)$ and the total neuritic length $(B)$ were plotted as a fraction of neurites (vertical axis) at a specific length measured in micrometers (horizontal axis). Both the length of the longest neurite $(A)$. and the total neuritic length $(B)$ were significantly greater on flat astrocytes as compared to rocky astrocytes after each comparable time point (48 or $72 \mathrm{hr})(p<$ 0.001 ; Mann-Whitney test).

longest neurite and the total neuritic length increased on flat and rocky substrates during the course of the experiment, demonstrating that the neurites were growing on both kinds of astrocyte. Second, the neurites were shorter on the rocky substrate than on the flat substrate at each time point examined, indicating that rocky astrocytes are a less permissive outgrowth substrate. The fact that the plots are practically superimposable for process extension on the rocky substrate after $48 \mathrm{hr}$ and the flat substrate after $24 \mathrm{hr}$ suggests that outgrowth is initially retarded on rocky astrocytes by approximately $1 \mathrm{~d}$. Neurites then began to grow, but at a slower rate than on flat astrocytes; therefore, some early event in neurite generation may have been inhibited more than

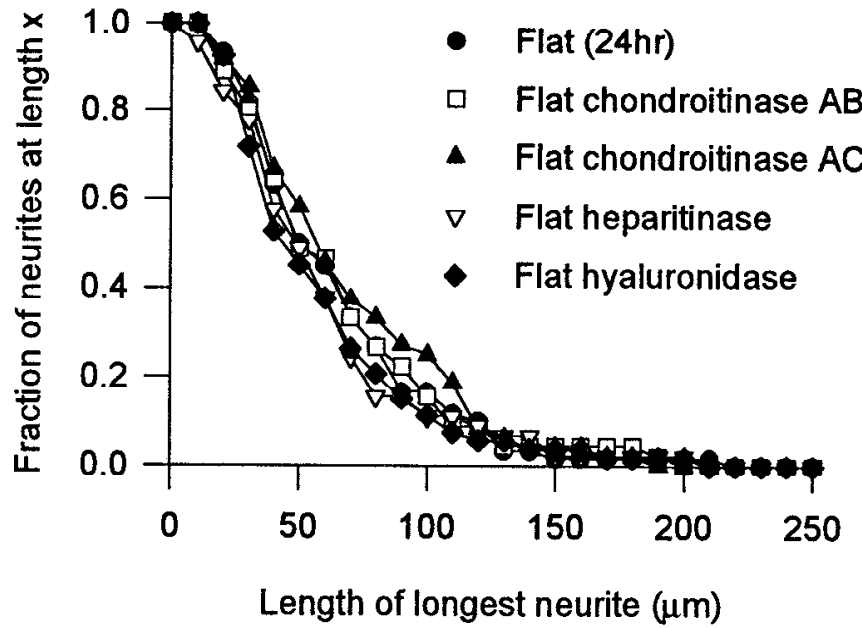

Figure 10. Effects of enzyme treatment on the neurite outgrowth-promoting ability of flat astrocytes. E15 mesencephalic cells were plated onto confluent control (untreated) monolayers or monolayers treated with chondroitinase $\mathrm{ABC}$, chondroitinase $\mathrm{AC}$, heparitinase, or hyaluoronidase. Outgrowth was measured at $24 \mathrm{hr}$. Distributions of the length of the longest neurite werc plotted as in Figure 9. This parameter was not significantly affected by prior exposure to enzymes.

process outgrowth itself, once established. In other experiments, similar outgrowth values were obtained using E17 cerebral cortical cells instead of E15 mesencephalic cells (data not shown), again suggesting that the different growth promoting abilities of flat and rocky astrocytes are due to astrocytic and not neuronal qualities.

\section{Neurite outgrowth on enzyme-treated astrocytes}

To determine if the differential ability of the two astrocyte subpopulations to support neurite outgrowth was correlated with CSPG glycosaminoglycan (GAG) chains, astrocytes were first treated with chondroitinase $\mathrm{ABC}$ or $\mathrm{AC}$ as described in Materials and Methods. They were also treated with heparitinase and hyaluronidase to investigate the relative contributions of HSPG GAGs and hyaluronic acid. Dissociated E15 mesencephalic cells were plated onto confluent monolayers of enzyme-treated astrocytes and untreated controls, and the extent of neurite outgrowth was determined at 24 and 48 hr. There was no significant difference in the distribution of the length of the longest neurite or the total neuritic length for neurons grown on enzyme-treated flat astrocytes in comparison to controls at either 24 or $48 \mathrm{hr}$; this is shown in Figure 10 for the length of the longest neurite at $24 \mathrm{hr}$. These results suggest that chondroitin/heparan sulfate GAGs and hyaluronic acid do not play major roles in regulating neurite outgrowth on flat astrocytes.

On rocky astrocytes, the vast majority of neurons demonstrated no outgrowth after $24 \mathrm{hr}$; likewise, no outgrowth was seen on rocky astrocytes at $24 \mathrm{hr}$ following heparitinase or hyaluronidase treatment. Heparitinase and hyaluronidase treatment also did not significantly affect outgrowth on rocky astrocytes at 48 hr (data not shown). Early experiments have demonstrated that flat and rocky astrocytes contain similar levels of HSPGs, but that the HSPG levels are quite low in comparison to levels of other neurite outgrowth-promoting molecules such as laminin or fibronectin (data not shown); therefore, the HSPG concentration in the matrix may not be high enough to affect the overall permisivity of the substrate. 


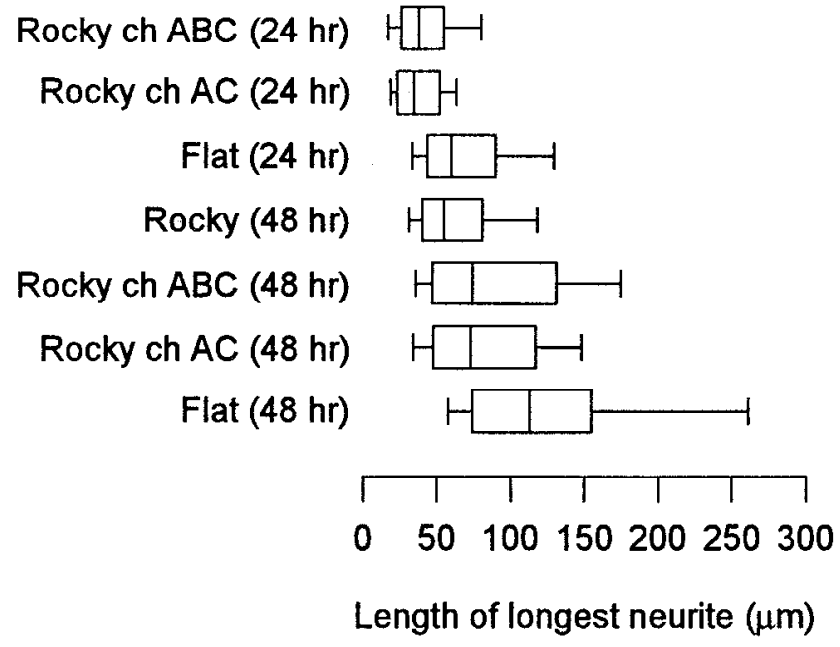

Figure 11. Effects of chondroitinase treatment on the neurite outgrowth-promoting ability of rocky astrocytes. E15 mesencephalic cells were plated onto confluent monolayers of flat astrocytes, rocky astrocytes, or rocky astrocytes treated with chondroitinase $\mathrm{ABC}$ (ch $A B C$ ) or $\mathrm{AC}$ ( $c h A C$ ). Outgrowth was measured at 24 and $48 \mathrm{hr}$. Box-andwhisker plots show distributions of the length of the longest neurite on each type of substrate. Boxes enclose 25 th and 75 th percentiles of each distribution and are bisected by the median; whiskers indicate 5th and 95 th percentiles. Treatment with either chondroitinase $\mathrm{ABC}$ or $\mathrm{AC}$ increased neurite outgrowth on rocky astrocytes; however, flat astrocytes are still a more favorable substrate for neurite outgrowth.

Chondroitinase treatment allowed some neurite outgrowth on rocky astrocytes at $24 \mathrm{hr}$, although it was not as robust as that observed on flat astrocytes. Figure 11 presents a box-and-whisker plot of the lengths of the longest neurite for neurons grown on control and chondroitinase-treated rocky astrocytes; this plot demonstrates that the median length of the longest neurite was $38 \mu \mathrm{m}$ on chondroitinase ABC-treated astrocytes, $33 \mu \mathrm{m}$ on chondroitinase AC-treated astrocytes, and $60 \mu \mathrm{ml}$ on flat astrocytes. Growth on rocky astrocytes at $48 \mathrm{hr}$ was similar to growth on flat astrocytes at $24 \mathrm{hr}$. Neuritic length at $48 \mathrm{hr}$ was increased for neurons growing on chondroitinase ABC or AC-treated rocky astrocytes, but again, the median length of the longest neurite was greatest for neurons grown on flat astrocytes. Longer periods of chondroitinase treatment (up to $10 \mathrm{hr}$ ) did not yield any further increases in outgrowth (data not shown). This suggests that CSPG GAGs in the rocky ECM are indeed inhibitory to neurite outgrowth but that they are not the only factor ac counting for the differences in flat and rocky astrocytes. The fact that similar results were obtained with either chondroitinase $\mathrm{ABC}$ or $\mathrm{AC}$ also suggests that DS does not contribute significantly to the rocky phenotype. In this experiment, total neuritic length followed the same trend as the length of the longest neurite (data not shown).

\section{Neurite outgrowth on extracellular matrix}

To verify a role for the rocky ECM in the inhibition of neurite outgrowth, dissociated E15 mesencephalic cells were plated onto matrix prepared from flat and rocky astrocytes and allowed to extend processes for 24 or $48 \mathrm{hr}$. The extent of neurite outgrowth was then determined. A box-and-whisker plot of the total neurite lengths is shown in Figure 12; this plot also incorporates outgrowth data replotted from Figure 9 for neurons grown on intact, living cells. Outgrowth on matrix was similar to outgrowth on intact, living cells in that no outgrowth occurred on rocky matrix

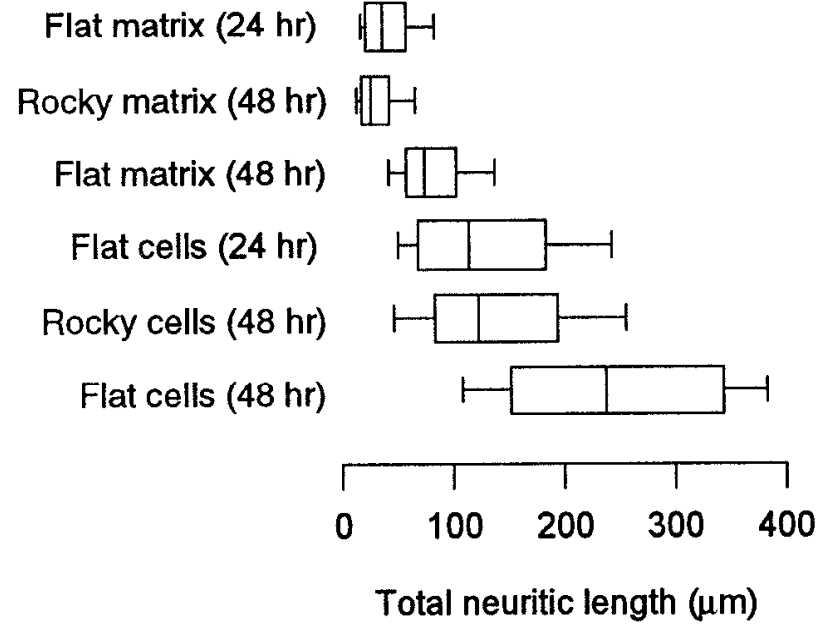

Figure 12. Neurite outgrowth on extracellular matrix. E15 mesencephalic cells were plated onto matrix prepared from confluent monolayers of flat or rocky astrocytes and allowed to extend processes for 24 or $24 \mathrm{hr}$. Box-and-whisker plots show distributions of the total neuritic length on each type of substrate. Neurite outgrowth on intact, living cells was replotted from the data in Figure 9. Neurite outgrowth on living astrocytes was greater than on corresponding matrix fractions.

at $24 \mathrm{hr}$, whereas flat matrix did permit outgrowth. Also similar to cells, outgrowth was comparable on rocky matrix at $48 \mathrm{hr}$ and flat matrix at $24 \mathrm{hr}$, although values were slightly lower (as opposed to nearly identical in the case of cells) on rocky matrix. In this experiment, the length of the longest neurite for neurons grown on matrix and cells followed the same trend as the total neuritic length (data not shown).

Outgrowth was always lower on matrix than on the corresponding living cells; for example, the median total neuritic length for neurons grown on flat matrix for $48 \mathrm{hr}$ was $60 \mu \mathrm{m}$ (in comparison to $250 \mu \mathrm{m}$ on flat astrocytes), and the median total neuritic length for neurons grown on rocky matrix for 48 hr was $18 \mu \mathrm{m}$ (in comparison to $115 \mu \mathrm{m}$ on rocky astrocytes). This suggests that both kinds of cells produce soluble products not found in matrix that stimulate neuronal growth. The difference between cells and matrix was larger for flat astrocytes than for rocky astrocytes (Fig. 12), which could be interpreted to mean that the former produce a larger ratio of soluble neuritcoutgrowth promoting versus inhibiting factors.

\section{Discussion}

Purified populations of rocky and flat astrocytes, following isolation from mixed monolayers, demonstrate significant differences in morphology and functional interactions with neurons. Rocky astrocytes, as well as matrix prepared from these astrocytes, are poor substrates for neuronal adhesion and process outgrowth. Consistent with this data, rocky astrocytes express high levels of tenascin and CS-6-PG, ECM molecules believed to be inhibitory for axon growth, whereas flat astrocytes express low levels of these molecules. Taken together, these properties of rocky astrocytes suggest that they represent a distinct phenotype of type- 1 astrocytes.

Previous classifications of cultured astrocytes have depended upon differences in either lineage, cellular morphology or antigenicity. For example, the type-2 astrocyte was distinguished by its stellate, process-bearing morphology and cross-reactivity with the antibody A2B5 (Eisenbarth et al., 1979) but not the 
antibody Ran-2 (Bartlett et al., 1981); flat type-1 astrocytes, in contrast, reacted with Ran-2 but not A2B5. An additional type of astrocyte, which has a flat, spread morphology with many cytoplasmic processes (Vaysee and Goldman, 1992), has been identified in rat CNS cultures. This astrocyte is antigenically distinct from the type-1 astrocyte, in that it binds GD3 ganglioside and may also bind A2B5. Miller and Szigeti (1991) have identified five morphologically distinct astrocyte lineages in spinal cord cultures; each of these lineages displayed heterogeniety in antigenicity toward A2B5 and Ran-2. Similar to these previous classifications, rocky and flat astrocytes can be differentiated morphologically, as well as antigenically by their heterologous expression of ECM molecules. Furthermore, functional assays which demonstrate the restrictive nature of rocky astrocytes toward the growth of CNS ncurons provides a ncw criterion with which to classify cultured astrocytes.

The unequivocal identification of a cultured astrocyte with its in vivo counterpart is dependent upon unique molecular markers. In the absence of such markers, the only data available are correlative. In this vein, both the functional and antigenic properties of rocky astrocytes are reminiscent of glia found in normal boundary regions of the embryonic and early postnatal CNS, such as the developing somatosensory cortical barrel fields (C.rossin et al., 1989; Steindler et al., 1989) and the dorsal root entry zone of the spinal cord (Pindzola et al., 1993). Astrocytes in these regions are characterized by a high expression of tenascin and CS-6-PG (Steindler et al., 1989, 1990; Snow et al., 1990b; Pindzola et al., 1993). High levels of these molecules have also been identified in the neonatal subventricular zone (SVZ) (McKeon et al., 1991; Gates et al. 1995) where they may form boundaries to regulate neuronal migration (Gates et al. 1995). Because our dissection procedure may include this region, the tenascin/CS-6-PG-rich rocky astrocytes may potentially represent subventricular cells.

Tenascin and CS-6-PG have both been shown to be inhibitory substrates for several types of CNS neurons in vitro (Faissner and Kruse, 1990; Snow et al., 1990a). Moreover, the combination of tcnascin and CS-6-PG has been suggested to be particularly repulsive to neuronal growth and regeneration (Newgreen et al., 1986, 1990; McKeon et al., 1991). These molecules are upregulated in response to CNS injury and may contribute to a chemical barrier provided by glial scars (McKeon et al., 1991; Pindzola et al., 1993). In support of this hypothesis, McKeon and Silver (McKeon and Silver, 1992) have shown that disruplion of CS-6-PG on glial scars via chondroitinase treatment creates a more permissive environment for neurite outgrowth. In a similar fashion, chondroitinase treatment increased the ability of rocky astrocytes to promote neurite outgrowth, but not to the extent of flat astrocytes. Therefore, in addition to CSPG GAGs, other molecules expressed by rocky astrocytes must limit neurite outgrowth. Obvious candidate molecules include tenascin, CSPG core proteins or soluble factors; however, our attempts to alter neurite outgrowth on rocky astrocytes through the use of tenascin antibodies have not been successful. Altcrnativcly, rocky astrocytes may lack positive regulators present in flat astrocytes.

The original identification of the rocky astrocyte as boundaryforming was based on the inability of neurites to cross from flat to rocky regions in mixed cultures (Grierson et al., 1990). How a neuron reacts to a substrate is strongly dependent upon context. Thus, neurites avoid rocky patches in mixed cultures but will grow on the purified subpopulation. This is similar to neurite outgrowth on glial scars: in vivo, glial scars in the adult mammalian CNS prevent extension of damaged axons, whereas explant cultures of glial scars do permit some growth of embryonic neurites in vitro (McKeon et al., 1991). Thus, a boundary is created by the apposition of cells with different abilities to promote neuronal migration and neuritic growth. However, not all neurons respond identically to the same cues. For example, embryonic cerebral cortical neurons appear to avoid a CSPG-rich region of the cortical plate, while thalamocortical afferents segregate within this region (Bicknese et al., 1994).

The complete set of stimuli that induce boundary formation both during development and after injury are as yet unknown. We have previously proposed a major role for cytokines (Meiners et al., 1993); for example, basic fibroblast growth factor (bFGF), which is present in high levels during CNS development (Caday et al., 1990; Heuer et al., 1990; Reid et al., 1990), upregulates both tenascin (Meiners et al., 1993) and CS-6-PG (our unpublished results) on cultures of neonatal astrocytes. Thus, bFGF may be responsible for the high levels of these proteins found in normal boundary zones. (It should be noted that cultures used in our previous study consisted only of flat astrocytes, and that the observed changes in astrocyte physiology were reversible and dependent on the physical presence of the cytokine: hence, bFGF treatement does not cause a flat astrocyte to "become" a rocky astrocyte.) Basic FGF and other cytokines are again elevated following CNS injury (Finkelstein et al., 1988), where they may promote the formation of glial scars and the concomitant increase in tenascin and CS-6-PG. On the other hand, only a subpopulation of scar-forming astrocytes express high levels of tenascin in vivo (Laywell et al., 1992), which implies a heterogenicty in their responsivencss to cytokines. Likewise, the heterogeniety of rocky and flat astrocytes in culture may reflect a differential response to the culture environment.

Finally, the question arises as to whether rocky and flat astrocytes represent different types of glial cells (which would imply an intrinsic difference in genotype or lineage) or different states of the same cell. The data presented within this study support the idea that rocky and flat astrocytes may represent different subtypes of astrocytes, in that subcultured rocky cells breed rocky and flat cells breed flat. We have also noted that the subcultured cells do not change their general morphology even after 3-4 months in vitro, that is, rocky cells do not become flat and flat cells do not become rocky (unpublished data). The fact that these cultures were neuron-free also eliminates contact with neurons as promoting a change in phenotype. On the other hand, while the low density culture techniques utilized in this study ensured that most of the subcultured flat and rocky cells were plated down as single cells, some of the cells may have remained in contact with one another or in close enough proximity to other cells to provide homotypic epigenetic signalling to maintain a particular phenotype. The question then becomes whether or not an isolated rocky or flat cell will produce a similar rocky or flat daughter ccll in the absence of any external environmental cues.

Our initial experiments with single-cell cloning analysis (Temple and Raff, 1986) of cerebral cortical astrocytes have revealed cells with several distinct morphologies, including some with a flattened, angular soma ("flat") and others with an elongated, process-bearing soma ("rocky") (unpublished data). These isolated astrocytes give rise to progeny with the same morphology. In addition, we have found that embryonic neurons have a propensity to extend processes on isolated "flat" cells but not on 
"rocky" cells. While these data also support the hypothesis that flat and rocky astrocytes represent different subtypes of cells, more detailed biochemical analyses and neuronal growth assays will be necessary to ascertain that the single-cell clones do actually correspond to the flat and rocky astrocytes characterized in the current study.

Whether distinct subtypes or different states, "rocky" and "flat" astrocytes are unique from one another in their expression of ECM and their ability to support neuronal growth. The inhibitory nature of the rocky astrocytes may be due in part to increased levels of tenascin and CS-6-PG on their surface, or it may be due to other as yet undefined attributes. The ability to grow purified cultures of these astrocytes should facilitate the identification of those molecules that are differentially expressed. Moreover, identification of a unique molecular marker for rocky astrocytes will allow us to test the proposition that rocky astrocytes represent a type of high tenascin/CS-6-PG astrocyte which appears during CNS development and is correlated with the maintenance of discrete migration tracts and that a similar kind of astrocyte reappears following injury. As such, rocky astrocytes provide a potentially valuable tool for the elucidation of astrocytic properties that inhibit neuronal growth and regeneration, for the exploration of the relative significance of ECM molecules as opposed to other astrocytic properties in regenerative failure, and for the development of therapies to mitigate reactive gliosis.

\section{References}

Barbin G, Katz DM, Chamak B, Glowinski J, Prochiantz A (1988) Brain astrocytes express region-specific surface glycoproteins in culture. Glia 1:96-103.

Bartlett PF, Noble M, Pruss RM, Raff MC, Rattray S, Williams CA (1981) Rat neural antigen-2 (Ran-2): a cell surface antigen on astrocytes, ependymal cells, Muller cells and leptomeninges defined by a monoclonal antibody. Brain Res 204:339-351.

Bicknese AR, Sheppard AM, O'Leary DD, Pearlman AL (1994) Thalamocortical axons extend along "a chondroitin sulfate proteoglycanenriched pathway coincident with the neocortical subplate and distinct from the efferent path. J Neurosci 14:3500-3510.

Bignami A, Eng LF, Dahl D, Uyeda CT (1972) Localization of the glial fibrillary acidic protein in astrocytes by immunofluorescence. Brain Res 43:429-435.

Bixby JL, Lilien J, Reichardt LF (1988) Identification of the major proteins that promote neuronal process outgrowth on Schwann cells in vitro. J Cell Biol 107:353-361.

Caday CG, Klagsbrun M, Fanning PJ, Mirzabegian A, Finkelstein SP (1990) Fibroblast growth factor (FGF) levels in the developing rat brain. Dev Brain Res 52:241-246.

Chiquet-Ehrismann R, Mackie EJ, Pearson CA, Sakakura T (1986) Tenascin: an extracellular matrix protein involved in tissue interactions during fetal development and oncogenesis. Cell 47:131-139.

Crossin KL, Hoffman S, Grumet M, Thiery J-P, Edelman GM (1986) Site-restricted expression of cytotactin during development of the chicken embryo. J Cell Biol 102:1917-1930.

Crossin KL, Hoffman S, Tan SS, Edelman GM (1989) Cytotactin and its proteoglycan ligand mark structural and functional boundaries in somatosensory cortex of the early postnatal mouse. Dev Biol 136: 381-392.

Eisenbarth GS, Walsh FS, Nirenberg M (1979) Monoclonal antibody to a plasma membrane antigen of neurons. Proc Natl Acad Sci USA 76:4913-4917.

Faissner A, Kruse J (1990) J1/tenascin is a repulsive substrate for central nervous system neurons. Neuron 5:627-637.

Fawcett JW, Housden E, Smith-Thomas L, Meyer RL (1989) The growth of axons in three-dimensional astrocyte cultures. Dev Biol 135:449-458.

Finkelstein SP, Apostolides PJ, Caday CG, Prosser J, Philips MF, Klagsbrun $M$ (1988) Increased basic fibroblast growth factor (bFGF) im- munoreactivity at the site of focal brain wounds. Brain Res 460:253259.

Gates MA, Thomas LB, Howard EM, Laywell ED, Sajin B, Faissner A, Gotz B, Silver J, Steindler DA (1995) Cell and molecular analysis of the developing and adult mouse subventricular zone of the cerebral hemisphere. J Comp Neurol, in press.

Grierson JP, Petroski RE, Ling DSF, Geller IIM (1990) Astrocyte topography and tenascin/cytotactin expression: correlation with the ability to support neuritic outgrowth. Dev Brain Res 55:11-19.

Grumet M, Kutishauser U, Edelman GM (1983) Neuron-glia adhesion is inhibited by antibodies to neural determinants. Science 222:60-62.

Heuer JG, Von Bartheld CS, Kinoshita Y, Evers PC, Bothwell M (1990) Alternating phases of FGF receptor and NGF receptor expression in the developing chicken nervous system. Neuron 5:283-296.

Johnstone SR, Levi G, Wilkin G, Schneider A, Ciotti MT (1986) Subpopulations of rat cerebellar astrocytes in primary culture: morphology, cell surface antigens and (3H)GABA transport. Dev Brain Res 24:63-75.

Laemmli UK (1970) Cleavage of structural proteins during the assembly of the head of bacteriophage T4. Nature 227:680-685.

Laywell ED, Dorries U, Bartsch U, Faissner A, Schachner M, Steindler DA (1992) Enhanced expression of the developmentally regulated extracellular matrix molecule tenascin following adult brain injury. Proc Natl Acad Sci USA 89:2634-2638.

McCarthy KD, De Vellis J (1980) Preparation of separate astroglial and oligodendroglial cell cultures from rat cerebral tissue. J Cell Biol 85:890-902.

McKeon RJ, Silver J (1992) Increased neurite outgrowth on glial scars following enzymatic digestion of chondroitin sulfate proteoglycan. Soc Neurosci Abstr 18:268.2.

McKeon RJ, Schreiber RC, Rudge JS, Silver J (1991) Reduction of neurite outgrowth in a model of glial scarring following CNS injury is correlated with the expression of inhibitory molecules on reactive astrocytes. J Neurosci 11:3398-3411.

Meiners S, Marone M, Rittenhouse JL, Geller HM (1993) Regulation of astrocytic tenascin by basic fibroblast growth factor. Dev Biol 160: 480-493.

Miller RH, Szigeti V (1991) Clonal analysis of astrocyte diversity in neonatal rat spinal cord cultures. Development 113:353-362.

Mirsky R, Winter J, Abney ER, Pruss RM, Gavrilovic J, Raff MC (1980) Myelin-specific proteins and glycolipids in rat schwann cells and oligodendrocytes in culture. J Cell Biol 84:483-494.

Neugebauer KM, Emmett CJ, Venstrom KA, Reichardt LF (1991) Vitronectin and thrombospondin promote retinal neurite outgrowth: developmental regulation and role of integrins. Neuron 6:345-358.

Newgreen DF, Scheel M, Kastner V (1986) Morphogenesis of sclerotome and neural crest in avian embryos: in vivo and in vitro studies of the role of notochordal extracellular matrix material. Cell Tissue Res 244:299-313.

Newgreen DF, Powell ME, Moser B (1990) Spatiotemporal changes in HNK-1/L2 glycoconjugates on avian embryo somile and neural crest cells. Dev Biol 139:100-120.

O'Shea KS, Rheinheimer JST, Dixit VM (1990) Deposition and role of thrombospondin in the histogenesis of the cerebellar cortex. J Cell Biol 110:1275-1283.

Peters A, Palay S, Webster H (1991) The fine structure of the nervous system: neurons and their supporting cells. New York: Oxford UP.

Petroski RE, Geller HM (1994) Selective labeling of embryonic neurons cultured on astrocyte monolayers with 5(6)-carboxyfluorescein diacetate (CFDA). J Neurosci Methods 52:23-32.

Petroski RE, Grierson JP, Choi-Kwon S, Geller HM (1991) Basic fibroblast growth factor regulates the ability of astrocytes to supporl hypothalamic neuronal survival in vitro. Dev Biol 147:1-13.

Pindzola RR, Doller C, Silver J (1993) Putative inhibitory extracellular matrix molecules at the dorsal root entry zone of the spinal cord during development and after root and sciatic nerve lesions. Dev Biol $156: 34-48$.

Raff MC (1989) Glial cell diversification in the rat optic nerve. Science 243:1450-1455.

Raff MC, Abncy ER, Cohen J, Lindsay R, Noble M (1983) Two types of astrocytes in cultures of developing rat white matter: differences in morphology, surface gangliosides, and growth characteristics. J Neurosci 3:1289-1300.

Rakic P (1971) Neuron-glia relationship during granule cell migration 
in developing cerebellar cortex. A Golgi and electron microscopic study in Macacus rhesus. J Comp Neurol 141:283-312.

Ramon y Cajal S (1909) Histologie du systeme nerveux de l'homme et des vertebres. Paris: Maloine.

Rauch U, Gao P, Janetzko A, Flaccus A, Hilgenberg L, Tekotte H, Margolis RK, Margolis RU (1991) Isolation and characterization of developmentally regulated chondroitin sulfate and chondroitin/keratan sulfate proteoglycans of brain identified with monoclonal antibodies. J Biol Chem 266:14785-14801.

Rauch U, Karthikeyan L, Maurel P, Margolis RU, Margolis RK (1992) Cloning and primary structure of neurocan, a developmentally regulated, aggregating chondroitin sulfate proteoglycan of brain. J Biol Chem 267:19536-19547.

Reid HH, Wilks AF, Bernard O (1990) Two forms of the basic fibroblast growth factor receptor-like mRNA are expressed in the developing mouse brain. Proc Natl Acad Sci USA 87:1596-1600.

Silver J, Lorenz SE, Wahlsten D, Coughlin J (1982) Axonal guidance during development of the great cerebral commissures: descriptive and experimental studies, in vivo, on the role of preformed glial pathways. J Comp Neurol 210:10-29.

Smith GM, Rutishauser U, Silver J, Miller RH (1990) Maturation of astrocytes in vitro alters the extent and molecular basis of neurite outgrowth. Dev Biol 138:377-390.

Smith-Thomas L, Fok-Seang J, Stevens J, Du J-S, Muir E, Faissner A, Geller HM, Rogers JH, Fawcett JW (1994) An inhibitor of neurite outgrowth produced by astrocytes. J Cell Sci 107:1-9.

Snow DM, Lemmon V, Carrino DA, Caplan AI, Silver J (1990a) Sul- fated proteoglycans in astroglial barriers inhibit neurite outgrowth in vitro. Exp Neurol 109:111-130.

Snow DM, Steindler DA, Silver J (1990b) Molecular and cellular characterization of the glial roof plate of the spinal cord and optic tectum: a possible role for a proteoglycan in the development of an axon barrier. Dev Biol 138:359-376.

Steindler DA, Cooper NG, Faissner A, Schachner M (1989) Boundaries defined by adhesion molecules during development of the cerebral cortex: the $\mathbf{J 1} /$ tenascin glycoprotein in the mouse somatosensory cortical barrel field. Dev Biol 131:243-260.

Steindler DA, O'Brien TF, Laywell E, Harrington K, Faissner A, Schachner M (1990) Boundaries during normal and abnormal brain development: in vivo and in vitro studies of glia and glycoconjugatcs. Exp Neurol 109:35-56.

Temple S, Raff MC (1986) Clonal analysis of oligodendrocyte development in culture: evidence for a developmental clock that counts cell divisions. Cell 44:773-779.

Towbin H, Staehelin T, Gordon J (1979) Electrophoretic transfer of proteins from polyacrylamide gels to nitrocellulose sheets: procedures and some applications. Proc Natl Acad Sci USA 76:4350-4354.

Trimmer PJ, McCarthy KD (1986) Immunocytochemically defined astroglia from fetal, newborn and young adult rats express B-adrenergic receptors in vitro. Dev Brain Res 27:151-165.

Vaysee PJ-J, Goldman JE (1992) A distinct type of GD3+, flat astrocyte in rat CNS cultures. J Neurosci 12:330-337.

Ventimiglia R, Geller HM (1987) Cell types and cell-substrate interactions in serum-free dissociated cultures of rat hypothalamus. Brain Res 436:339-351. 